range improved from $23 \%$ in 1976 to $68 \%$ in 1979. It seems likely. that more caesarean sections were performed, especially in this extremely low birthweight group, during the latter years of the study. The fact that both vertex and breech delivery in the 750-1000 g group carry an equally high mortality rate when compared with caesarean section lends further support to the suspicion that many factors other than breech presentation are responsible for the differences in survival rate.

This paper does not strengthen the case for a policy of caesarean section for all cases of breech presentation from 26 to 34 weeks. It does, however, lend further support to the case for a randomised controlled trial of caesarean section for preterm breech presentation, which was called for in this journal in $1979 .^{3}$

\section{Patricia Crowley}

National Perinatal Epidemiology Unit,

Radcliffe Infirmary,
Oxford OX2 $6 \mathrm{HE}$,

${ }^{1}$ Crowley P, Hawkins DF. F Obstet Gynaecol 1980; 1:2-6.

${ }^{2}$ Rush W, Keirse MJ, Howat $P$, Baum JD, Anderson AB, Turnbull AC. Br Med f 1976;ii :965-8.

${ }^{3}$ Anonymous. $B r$ Med $\mathcal{F} 1979 ; \mathrm{i}: 1747$.

${ }_{*}^{*}$ *We sent these letters to the authors, who reply below.-ED, BMF.

SIR,-We thank your correspondents for all their comments.

In reply to $\mathrm{Mr}$ House and Mr Pereira, in the original study we did record the indications for caesarean section and the complications that were associated with the vaginal deliveries. The incidence of severe pre-eclamptic toxaemia, antepartum haemorrhage, and multiple pregnancy, according to mode of delivery, is shown in the accompanying table. It is quite clear that the caesarean section group had a much higher complication rate than the vaginally delivered group, with the exception of the cases of multiple pregnancy. If multiple births are excluded from the figures, however, the overall results remain unchanged.

In reply to Dr Mathews, although we collected information about the indications for caesarean section recorded in the infants' notes we did not refer to the mothers' notes or operation sheets; so it is quite likely that some babies with breech presentation delivered by caesarean section have been overlooked, particularly when the breech presentation was unexpected or overshadowed by major complications meriting caesarean section. Nevertheless, out of 225 small babies delivered by caesarean section, 25 cases of breech presentation were identified. Of these, only six were uncomplicated, and in these the mortality was zero. A further 23 indications were recorded for the 19 remaining cases, some having more than one additional problem. These indications were as follows: pre-eclamptic toxaemia-five cases; antepartum haemorrhage-two; fetal distress-four; placental insufficiency-five; multiple pregnancyfour; cord prolapse-one; previous section-one; intrauterine growth retardation-one. In this group one baby was in the weight range $750-1000 \mathrm{~g}$; seven were $1001-1500 \mathrm{~g}$; and 17 were $1501-2000$, of whom two died-a death rate of $8 \%$ in the total group of 25 .

Complications according to mode of delivery and survival figures in infants $\leqslant 2000 \mathrm{~g}$

\begin{tabular}{|c|c|c|c|c|c|c|c|c|c|c|c|c|}
\hline \multirow[t]{2}{*}{ Type of delivery } & \multirow[t]{2}{*}{ Total No } & \multicolumn{4}{|c|}{ Multiple births } & \multicolumn{4}{|c|}{ Antepartum haemorrhage } & \multicolumn{3}{|c|}{ Pre-eclamptic totaemia } \\
\hline & & No & $(\%)$ & Deaths & $(\%)$ & No & $(\%)$ & Deaths & $(\%)$ & No & $(\%)$ & Deaths $(\%)$ \\
\hline $\begin{array}{l}\text { Vaginal } \\
\text { Vertex } \\
\text { Breech }\end{array}$ & $\begin{array}{l}401 \\
102\end{array}$ & $\begin{array}{l}70 \\
40\end{array}$ & $\begin{array}{l}(17) \\
\text { (39) }\end{array}$ & $\begin{array}{l}10 \\
13\end{array}$ & $\begin{array}{l}(14) \\
\text { (32) }\end{array}$ & $\begin{array}{l}28 \\
10\end{array}$ & $\begin{array}{l}(7) \\
(10)\end{array}$ & $\begin{array}{l}5 \\
8\end{array}$ & $\begin{array}{l}(17) \\
(80)\end{array}$ & $\begin{array}{r}14 \\
0\end{array}$ & $\begin{array}{c}(3) \\
(-)\end{array}$ & $\begin{array}{l}0 \\
0\end{array}$ \\
\hline $\begin{array}{l}\text { Caesarean Section } \\
\text { Vertex } \\
\text { Breech }\end{array}$ & $\begin{array}{r}202 \\
23\end{array}$ & $\begin{array}{r}34 \\
4\end{array}$ & $\begin{array}{l}(17) \\
(17)\end{array}$ & $\begin{array}{l}6 \\
1\end{array}$ & $\begin{array}{l}(18) \\
(25)\end{array}$ & $\begin{array}{r}43 \\
2\end{array}$ & $\begin{array}{r}(21) \\
(9)\end{array}$ & $\begin{array}{l}0 \\
7\end{array}$ & (16) & $\begin{array}{r}66 \\
5\end{array}$ & $\begin{array}{l}(33) \\
(22)\end{array}$ & $\begin{array}{c}3 \\
(0)\end{array}$ \\
\hline
\end{tabular}

We are sure that Dr Mathews would agree that the list of complications is formidable, and although the numbers are small the results from caesarean section under these circumstances are very favourable, thus lending support to our original hypothesis that the mortality rate in preterm infants with breech presentation is considerably improved if they are delivered by caesarean section. The only other factor which might tend to favour caesarean section, apart from the mode of delivery itself, is the fact that mothers presenting in the second stage will in most cases have selected themselves for vaginal delivery, and yet at the same time have denied themselves the benefits of expert management during the course of their labour.

We will attempt to qualify the "unqualified" generalisations for which Mr Selwyn Crawford criticised us. Of course, all retrospective studies have traps-we did not deny this in our articleand we are aware of the many interrelated factors associated with neonatal mortality. The purpose of this study was not to relate the anaesthetic procedure with the outcome and thus we cannot answer the specific questions related to the anaesthetic technique. We were primarily concerned with presenting the data related to the infants of very low birth weight whose survival rate has increased dramatically in the last few years, and the conclusions therefore cannot be dismissed, except by prophets, as "generalisations well appreciated for many years." However, some of the points raised by $\mathrm{Mr}$ Crawford we are able to answer. Firstly, emergency and elective caesarean sections were analysed separately but later grouped together because there was no difference between them. Secondly, the breech deliveries were assisted in the vast majority of cases. We have already dealt with the question regarding infants presenting in the breech position and delivered by caesarean section. Having criticised our generalisations $\mathrm{Mr}$ Crawford then treats us to his own and alludes to work without reference to any data. But we are glad he has set up a prospective study and look forward to seeing the results.

We would like to thank Patricia Crowley for her analysis, which is, of course, valid. Many of the other points that have been raised we accept, but within the context of the retrospective nature of the study the answers cannot be obtained. Therefore we are bound to agree with the conclusion of Ms Crowley that a randomised controlled trial of caesarean section for preterm breech presentations is called for, and it is our hope that someone will accept the challenge of a very difficult trial.

Bradford Children's Hospital,
Bradford, Yorks BD8 7QF

M L SMITH

S A SPENCER

University Department of Child Health Nottingham NG7 2UH

\section{Intrinsic hazard of breech presentation}

SIR,-Mr John P Calvert (15 November, p 1319) showed that delivery by elective lower segment caesarean section at term results in higher incidences of low Apgar scores and intubation when the fetus presents by the

SIR,-Nurses need not be involved in the administration of prostaglandin when the extra-amniotic route is used by the following technique.

A $0.5 \mathrm{ml}$ ampoule of Prostin E, dissolved in $50 \mathrm{ml}$ of the solution supplied with the ampoule, is added to $1000 \mathrm{ml}$ of normal saline. A No 16 Foley catheter with a $30 \mathrm{ml}$ balloon is filled with infusion fluid and clamped off at one end, so that the fluid does not run out. The breech. No data about subsequent neonatal special care unit, or feeding behaviour are delivery by lower segment caesarean section the dangerous when the fetus presents by to consider delivery by classical caesarean ection.

breech at caesarean section is avoided with halothane, which relaxes the contracting thick uterine wall. ${ }^{1}$

Department of

M J JOHNSTONE

Western General Hospital,

' Johnstone MJ. Br Med F 1979;ii:1222. SIR,-Thank you for offering me the opportunity to reply to $\mathrm{Mr} \mathrm{M} \mathrm{J}$ Johnstone.

We did study a number of postnatal factors related to neonatal wellbeing but found no differences except in the Apgar score and the as the pregnancies were uncomplicated by medical or obstetric pathology to impair fetal nutrition and oxygenation, and all the babies were normal babies of appropriate weigh .

study was planned to test the hypothesis lower-segment caesarean section, even under the best possible conditions, was more likely suffer neonatal depression than was his score was used because it is the most convenient, reproduceable, and widely used assessment of the neonate; and the relationship between depressed Apgar scores at both one and five minutes and subsequent neurological The in heen clearly demonstrated. ${ }^{1}$ have shown is small, but could be important the fetus is already in jeopardy.

$\mathrm{Mr}$ Johnstone repeats his suggestion that the use of halothane will solve the problem of entrapment of the head of the preterm baby but offers no evidence either to support this or to show that the routine use of halothane have demonstrated.

Department of Obstetrics and

Medicine,

1 Drage DS, Berendes H. Pediatr Clin N Am 1966;13: 635-43.

Drage JS, Kennedy C, Berendes H, Schwarz BK
Weiss W. Develop Med Child Neurol 1966;8:141. ${ }^{3}$ Johnstone MR. Br Med J 1979;ii:1222.

\section{Prostaglandin termination of pregnancy} given and therefore it cannot be claimed that

$*_{*}^{*}$ We sent this letter to $\mathrm{Mr}$ Calvert, who 